\title{
O Festival Halleluya em Fortaleza (Ceará, Brasil) sob a ótica do planejamento e da gestão de eventos
}

\author{
The Halleluya Festival in Fortaleza (Ceará, Brazil) from the perspective of \\ planning and event management
}

\author{
Débora Cristina Costa (COSTA, D. C.) ${ }^{*}$, \\ Maria Helena Belchior (BELCHIOR, M. H.) ${ }^{* *} \mathrm{e}$ \\ Ana Julia Melo (MELO, A. J.) ${ }^{* * *}$
}

\begin{abstract}
RESUMO - O presente estudo surgiu a partir da percepção quanto à relevância dos eventos no segmento religioso no Brasil. Pelo fato de os festivais religiosos estarem diretamente ligados à cultura, realizou-se um estudo de caso no Festival Halleluya, evento que ocorre desde 1997 no país, mas que apresenta uma lacuna quanto à consolidação e, por conseguinte, também se percebeu a falta de dados que congreguem informações relativas ao planejamento, à organização e à execução do mesmo. Dada a expressividade do evento em termos de público, abrangência, periodicidade e parceiros e por poder servir como um ícone ao se tratar de Festivais de cunho cultural religioso no país, buscou-se então sistematizar as informações referentes à organização e ao planejamento do Festival Halleluya sediado em Fortaleza (Ceará/CE, Brasil). Tem-se uma pesquisa descritiva abrangendo a tipologia de estudo de caso, de abordagem quanti-qualitativa na realização dos procedimentos inerentes à pesquisa de campo somando-se a realização de pesquisa bibliográfica. Como principais resultados percebidos, foi possível pormenorizar as fases do evento no ano de 2015, identificar os voluntários como principais envolvidos na organização e na realização do festival, além de se constatar uma estabilização na quantidade de público participante e um acréscimo considerável nos números relativos a itens envoltos à questão da solidariedade.
\end{abstract}

Palavras-chave: Turismo; Organização de eventos; Eventos culturais-religiosos; Festival Halleluya.

\footnotetext{
* Formação: Graduação em Turismo pela Universidade Federal de Pernambuco (UFPE); Pós-graduanda de Especialização em Gestão, Planejamento e Organização de Eventos pela Universidade Norte do Paraná (UNOPAR). Atividade profissional: Agente de intercâmbio na Walk Abroad Intercâmbio. Endereço físico para correspondência: Rua Quatro de Março, 381. CEP: 52071-210 - Recife - Pernambuco (Brasil). Email: deboracristal2@hotmail.com

** Formação: Graduação em Turismo pela Universidade Federal de Pernambuco (UFPE), Especialista em Educação a Distância com Habilitação em Tecnologias Educacionais pelo Instituto Federal do Paraná (IFPR); Especialista em Administração de Marketing pela Universidade de Pernambuco (UPE), Mestrado em Gestão do Desenvolvimento Sustentável pela Universidade de Pernambuco (UPE). Atividade Profissional: Professora do Departamento de Hotelaria e Turismo do Centro de Ciências Sociais Aplicadas da Universidade Federal de Pernambuco (UFPE). Endereço físico para correspondência: Rua Professora Teresa Melias, s./n., Cidade Universitária. CEP: 50670-901 - Recife - Pernambuco (Brasil). Email: mhcavalcanti@gmail.com

*** Formação: Licenciatura em Educação Física pela Universidade Federal de Pernambuco (UFPE). Mestrado em Hospitalidade pela Universidade Anhembi Morumbi (UAM); Mestrado em Turismo pela Universidade Iberoamericana (UNIBERO). Atividade Profissional: Professora do Departamento de Hotelaria e Turismo do Centro de Ciências Sociais Aplicadas da Universidade Federal de Pernambuco (UFPE). Endereço físico para correspondência: Rua Conselheiro Nabuco, 151/202. CEP: 52070-010 Recife - Pernambuco (Brasil). E-mail: anjutur@gmail.com
} 
ABSTRACT - The present study emerged out of the perception about the relevance of religious events in the Brazil. Due the fact of religious festivals were directly linked to the culture, a case study was carried out in Festival Halleluya, an event that happen since 1997 in the country, but which shows a gap related to its consolidation and consequently it also presents lack of data related to its planning, organization and execution. Given the expressiveness of the event in relation to the public, coverage, periodicity and partners, and because this event is an icon when we talk about Festivals that has cultural and religious importance in the country, this paper sought to systematize the information regarding to the organization and planning of the Festival Halleluya that happens in Fortaleza (Ceará/CE, Brazil). Then, it presents a descriptive research approaching the typology of case study, with quantitative-qualitative procedures inherent to the field research and using bibliographical research. As main results: it was possible to detail the phases of the event in the year 2015, to identify volunteers as the main people involved in the organization and conduction of the festival, in addition it was verified stabilization in the number of participants and a considerable increase in the numbers related to the items which involve the people solidarity.

Key words: Tourism; Events organization; Religious-cultural events; Festival Halleluya. 


\section{INTRODUÇÃO}

O conceito de turismo estabelecido pela Organização Mundial de Turismo World Tourism Organization (UNW) em 1991 é compreendido como: “as atividades desenvolvidas pelas pessoas ao longo de viagens e estadas em locais situados fora do seu enquadramento habitual, por um período consecutivo que não ultrapasse um ano, para fins recreativos, de negócios, ou outros" (CUNHA, 1997, p. $9^{1}$ apud AGUIAR; DIAS, 2002).

Essas atividades responsáveis pelo deslocamento dos turistas podem ser motivadas, entre outros fatores, por eventos. O Plano Aquarela 2020, elaborado pelo Instituto Brasileiro de Turismo (EMBRATUR), traz dados do estudo da demanda turística internacional (2008) revelando que os eventos e negócios ocupavam a segunda posição quanto à motivação de viagens dos turistas internacionais, perfazendo $27 \%$, atrás somente do lazer, que possuiu 30\% (EMBRATUR, 2009).

Os eventos, segundo Hackbert $\left(2009^{2}\right.$ apud MACIEL, 2011, p. 6), "são oportunidades para divertimento e entretenimento artístico, cultural e patrimonial em comunidades e noutros locais recreativos", ou ainda, como afirma Zanella (2003, p. 13), eventos são:

\footnotetext{
Reuniões realizadas por um grupo de pessoas ou empresas em locais e datas definidos, tendo como objetivo celebrar acontecimentos importantes e significativos ou estabelecer contatos de natureza comercial, cultural, esportiva, social, familiar, religiosa, científica, etc.
}

Portanto, o setor de eventos movimenta todos os públicos dependendo da sua tipologia, assim como o turismo, de acordo com o perfil do seu destino receptor.

Dentro das naturezas apresentadas na definição de Zanella (2003) está a religiosa e, de acordo com Andrade (2002, p. 79), depois do turismo de férias e de negócios, o segmento que mais estava se desenvolvendo vinha sendo o turismo religioso, visto que “[...] além dos aspectos místicos e dogmáticos - as religiões assumem o papel de agentes culturais pelas manifestações de valores antigos, de intervenção na sociedade atual e de preservação no que diz respeito ao futuro dos indivíduos e das sociedades".

\footnotetext{
${ }^{1}$ CUNHA, L. Economia e política do Turismo. Lisboa: McGRAW-HILL, 1997.

${ }^{2}$ HACKBERT, P.H. Economic Impacts of Appalachian Festivals. ASBBS Annual Conference: Las Vegas, v. 16, n. 1, 2009.
} 
Silveira (2007 ${ }^{3}$ apud ARAGÃO; MACEDO, 2011, p. 405) elenca três tipos principais de manifestações religiosas pelas quais o turismo se utiliza: as que estão relacionadas ao patrimônio arquitetônico, como igrejas, templos, dentre outros; as dos rituais, onde se insere a celebração da Semana Santa; e as de eventos com suas festas religiosas e festivais de música. Este último tipo será analisado mais minuciosamente e tomado como objeto de estudo deste trabalho.

O Ministério do Turismo (2010, p. 19) entende o turismo religioso como um segmento específico do turismo cultural, considerando que o mesmo se formata "pelas atividades turísticas recorrentes à busca espiritual e prática religiosa em espaços e eventos segundo as religiões institucionalizadas, tais como as de origem católica [...] templos, rituais, e sacerdócio".

Por este motivo os festivais religiosos também estão diretamente ligados à cultura, como afirma Laopodi (2003 ${ }^{4}$ apud MACIEL, 2011, p. 8):

Desde a sua origem até aos dias de hoje, os festivais juntam pessoas e permitem-lhes expressar as suas preocupações e ansiedades enquanto lhes fornecem experiências culturais. Os festivais agrupam diferentes formas de atividades culturais e diferentes pessoas e promovem uma troca cultural e democrática.

Ao se analisar os festivais culturais-religiosos que acontecem no Brasil destacase um que tem sua edição principal ocorrendo na cidade de Fortaleza, estado do Ceará. (COSTA, 2015). Este festival consegue reunir 1 milhão de pessoas em cinco noites de evento (FESTIVAL HALLELUYA, 2015) e, segundo a organização geral, como publicado no portal de notícias da Comunidade Católica Shalom (COMSHALOM, 2015), é "o maior festival de artes integradas da América Latina”.

Intitulado "Festival Halleluya - A festa que nunca acaba" e organizado pela Comunidade Católica Shalom, o evento está em constante crescimento, tanto na organização, no aspecto do planejamento, da infraestrutura, das parcerias, do voluntariado, como na quantidade de público participante. Contudo, existe uma incipiente apresentação e disponibilização de dados sobre o evento em fontes confiáveis e que poderiam vir a ser utilizadas por aqueles desejosos em compreender a dinâmica

\footnotetext{
${ }^{3}$ SILVEIRA, E. S. da. Por uma sociologia do turismo. Porto Alegre: Zouk, 2007.

${ }^{4}$ LAOPODI, M. L. Cultural Democracy: The Way Festivals Affect Society. Florida: Dissertation.com., 2003.
} 
envolta ao Festival Halleluya, enquanto um megaevento cultural religioso de proporções ímpares.

Por essa razão, questões norteadoras para a preparação do estudo foram elencadas, tais como: Quem o organiza? Seriam profissionais qualificados? Por que e como um evento deste porte poderia ser gratuito? Como estaria ocorrendo a captação de recursos? Quem seriam os profissionais que trabalhavam durante o evento?

Assim, face ao exposto, emergiu a problemática presente neste estudo: como se deu a evolução do planejamento e organização do Festival Halleluya sediado em Fortaleza (Ceará/CE, Brasil)?

A partir desse questionamento foi traçado o objetivo de sistematizar informações referentes à organização e ao planejamento do evento.

\section{FUNDAMENTAÇÃO TEÓRICA}

Nesta seção serão apresentados "o estado do problema a ser pesquisado, sob o aspecto teórico" (LAKATOS; MARCONI, 2003, p. 215) com a intenção de se alcançar os objetivos propostos no estudo, enfatizando conceitos e características trazidos por diversos autores especialistas no tema em questão. Destaca-se ainda a relevância dos eventos ao turismo sob uma perspectiva mais operacional focando-se especialmente no planejamento e organização de eventos.

\subsection{A IMPORTÂNCIA DOS EVENTOS NO TURISMO}

Para conceituar evento de forma geral, Allen et al. (2008, p. 4) utilizam o recorte "evento especial", e o definem como sendo um "ritual, apresentação ou celebração específica, que tenha sido planejada com o intuito de marcar datas especiais ou atingir objetivos e metas de cunho social, cultural ou corporativo", sendo perceptível desde já a presença do planejamento. Para que um evento seja considerado especial, existe a necessidade de que alguns atributos sejam considerados, dentre eles: espírito festivo, singularidade, qualidade, autenticidade, tradição, hospitalidade, temática e simbolismo 
(GETZ, 1997; ALLEN et al., 2008; STOCK, 20095 apud BARBOSA, 2013, p. 91), destacando-o de outros eventos.

Wragg (1989, p. 57) enfatiza a importância do público, além de ressaltar evento como oportunidade de contato, afirmando que "os eventos não ocorrem isoladamente ou essencialmente em função das mídias, mas são uma oportunidade de contato direto com o público e isso não deve ser esquecido".

A presença da palavra-chave "público" utilizada pelos autores citados faz com que seja perceptível a importância deste para a realização de um evento, pois é para tal público específico que um evento é planejado e organizado, a fim de que seja alcançado um objetivo distinto que dependerá da organização, podendo ser para fins acadêmicos, intelectuais, de lazer, de negócios, entre outros.

Para Guibilato $\left(1983^{6}\right.$ apud CARDOSO, 2013, p. 16) eventos "são ações efetuadas pelo homem que levam pessoas a visitar e a deslocarem-se para o local", gerando impacto direto na cadeia produtiva do turismo.

Atualmente, já é possível identificar mais claramente o potencial que os eventos acarretam ao turismo, pois ajudam a reduzir sensivelmente a sazonalidade (VIDAL; RIEDL, 2016), além de criarem "uma imagem positiva da cidade sede; mobilizar o trade turístico e, por consequência, os prestadores de serviço, gerando emprego e renda de imediato; e a propiciar o ingresso de divisas para o país, estado ou cidade realizadora" (HOELLER, 2000, p. 77).

Simões e Pereira (2008 ${ }^{7}$ apud ANDRADE 2008, p. 30) esclarecem a importância dos eventos para o turismo do destino receptor:

Esta é a maior importância da realização de eventos: atrair uma demanda frequente, de forma sustentável e que se traduz em produtividade. Motivando e atraindo um número maior de turistas, a localidade estará mantendo a oferta ativa e operante, assegurando os empregos e o retorno financeiro e econômico.

\footnotetext{
5 STOCK, L. T. Logística Integrada em Eventos: um estudo de caso do Festival de Dança de Joinville/SC. Dissertação (Mestrado em Turismo e Hotelaria). Universidade do Vale do Itajaí, Balneário Camboriú, 2009.

${ }^{6}$ GUILIBATO, G. Economie Touristique. Collection Hotellerie \& Tourisme, Éditions Delta \& Spes, Suiça, 1983.

${ }^{7}$ SIMÕES, M. C. de M.; PEREIRA, M. L. B. F. A utilização de eventos como estratégia de marketing para o turismo. Disponível em:

<http://www.ficms.com.br/web/revista/arquivos/ArtigoRevistaVisaon15AUtilizacaodeEventoscomoEstrat egiadeMKT.doc>. Acesso em: 28/11/2008.
} 
Complementando, Molina (2013, p. 59) também traz dados importantes referentes aos benefícios para uma cidade, ao acrescentar, além do econômico, a infraestrutura e a consolidação da imagem do destino.

Ainda no que se refere à economia, vê-se que "o mercado de eventos no Brasil cresceu de forma expressiva nos últimos 12 anos no que se refere à geração de negócios, emprego, renda e impostos", como aponta o II Dimensionamento Econômico da Indústria de Eventos (ABEOC BRASIL, 2013, p. 6). Ainda no estudo supracitado, o segmento de eventos movimentou $\mathrm{R} \$ 209,2$ bilhões em 2013, o que representou uma participação do setor em 4,32\% no Produto Interno Bruto (PIB) do Brasil.

Em relação à distribuição geográfica dos eventos, a pesquisa revelou que a região sudeste brasileira continuava respondendo pela maior parte do mercado em tela, com a realização de 305.720 eventos (52\%), sendo seguida pela região nordeste com 116.362 eventos realizados (20\%). A região sul executou um total de 88.420 eventos (15\%), a região centro-oeste, $54.698(9 \%)$ e, por fim, a região norte implementou um total de 25.721 eventos (4\%).

Com isso, constata-se que o setor de eventos se encontra em constante crescimento, influenciando positivamente a cadeia produtiva do turismo e fazendo com que cada destino receptor se consolide e se qualifique cada vez mais para o recebimento de eventos de diversos portes.

Neste trabalho, o estudo de caso, além de ser realizado em um evento considerado como megaevento, também traz consigo a classificação enquanto festival, que é "uma forma universal de evento, anterior à indústria contemporânea de eventos, e existem na maioria das épocas e sociedade [...] contribui para a vida cultural e social, também estão cada vez mais ligados ao turismo" (ALLEN et al., 2008, p. 6).

Os festivais, desde sua origem até a atualidade, em sua realização "juntam pessoas e permitem-lhes expressar as suas preocupações e ansiedades enquanto lhes fornecem experiências culturais, eles agrupam diferentes formas de atividades culturais e diferentes pessoas e promovem uma troca cultural e democrática" (LAOPODI, $2003^{8}$ apud MACIEL, 2011, p. 8), além de transmitir 'felicidade e prazer público', tradução do latim para a palavra festival.

\footnotetext{
${ }^{8}$ LAOPODI, M. L. Cultural Democracy: The Way Festivals Affect Society. Florida: Dissertation.com, 2003.
} 
Dentro da dimensão do turismo cultural, o Ministério do Turismo do Brasil vem afirmar a existência de "formas de expressão da cultura que são classificadas em áreas de interesse específico e que geram demandas de viagem com motivação própria, [...] é o caso da religião" (BRASIL, 2010, p. 18) e ainda defender o turismo religioso como um segmento do turismo cultural, informando que o mesmo formata-se pela atividade turística ligada à "busca espiritual e prática religiosa em espaços e eventos segundo as religiões institucionalizadas" (BRASIL, 2010, p. 19), estando dentre elas, a religião católica, da qual faz parte o evento analisado.

Aqui se faz perceptível a ligação direta que o turismo cultural-religioso possui com os eventos culturais-religiosos, pois as práticas religiosas normalmente acontecem em eventos tornando-os grandes motivadores para o deslocamento das pessoas. Na concepção de Ferreira (2009, p. 17), a comemoração religiosa "é um momento de celebração da vida, que rompe o ritmo monótono do cotidiano, e permite a vivência de afetos e emoções". Ainda segundo a autora, as festas de caráter religioso "também perpetuam as tradições e constituem um verdadeiro patrimônio cultural".

Silveira e Dias (2003, p. 17) também tratam dos eventos religiosos como expressões culturais e afirmam que apresentam características semelhantes:

\footnotetext{
O turismo religioso apresenta características que coincidem com o turismo cultural, devido à visita que ocorre num entorno considerado como patrimônio cultural, os eventos religiosos constituem-se em expressões culturais de determinados grupos sociais ou expressam uma realidade histórico-cultural expressiva e representativa de determinada região.
}

Diante da concordância dos autores de que o turismo religioso está inserido no contexto do turismo cultural, e incluso nesse grupo os eventos religiosos, faz-se necessário um breve estudo das etapas do planejamento e organização de eventos.

\subsection{PLANEJAMENTO E ORGANIZAÇÃO DE EVENTOS}

Antes da realização de qualquer evento se faz indispensável o planejamento para que a organização possa acontecer da melhor forma possível, pois ela "é trabalhosa e exige grande responsabilidade. Acontece ao vivo, e qualquer falha comprometerá o conceito/imagem" do evento, da equipe organizadora e/ou até mesmo do destino (CESCA, 2008, p. 49). Porém, antes do planejamento do evento existe o planejamento 
estratégico, o qual se inicia com a compreensão de que a realização de um evento envolverá processos como pesquisa, planejamento, organização, coordenação, controle, além de se implantar um projeto a fim de se atingir um público-alvo com medidas concretas e resultados projetados (BRITO; FONTES, 2004).

Nos eventos, de acordo com o manual de organização de eventos do Senado Federal (BRASIL, 2013, p. 20), o planejamento consiste em "elaborar um projeto descritivo com os elementos essenciais para guiar a organização e a execução do evento", nele devem estar presentes os "objetivos, públicos, estratégias, recursos, implantação, fatores condicionantes, acompanhamento e controle, avaliação e orçamento" (CESCA, 2008, p. 49). Chega-se aqui a conclusão de que todo evento é um projeto, mas nem todo projeto é um evento.

Organizar um evento é executar todas as providências preparatórias necessárias para assegurar as melhores condições à sua realização, sem problemas administrativos, disciplinares e estruturais. "Para que isto ocorra, trabalhar com antecedência é uma das principais atitudes que se deve tomar" (POIT, 2006, p. 78).

Por mais simples que seja um evento e, para que esteja bem organizado, os organizadores costumam dividi-lo em fases ou etapas: pré-evento, evento e pós-evento. O pré-evento é o momento de se colocar em prática o planejamento, sendo geralmente norteado pela elaboração de um briefing ${ }^{9}$. O evento trata da realização da atividade programada em si, a hora mais aguardada pelo público participante e o pós-evento é o período em que toda a infraestrutura necessária à execução do evento é retirada e ocorrem as avaliações dos processos. Nessa etapa se torna possível analisar as decisões tomadas durante o evento (se foram adequadas ou não), além de se verificar o alcance do objetivo (ou não) do evento (ALLEN et al., 2008).

\section{PROCEDIMENTOS METODOLÓGICOS}

O presente trabalho foi estruturado primeiramente através de pesquisa bibliográfica, sendo a partir desta construído todo seu marco teórico. Buscaram-se, através da pesquisa, análise e interpretação de livros e artigos, dados concernentes à

\footnotetext{
${ }^{9}$ Trata-se de um resumo de informações, isto é, a identificação de todos os elementos essenciais e necessários para a organização do evento.
} 
conceituação e à caracterização dos eventos com a sua devida importância no campo do turismo, além das fases do planejamento e da organização.

Classifica-se enquanto seu objetivo como uma pesquisa descritiva, na qual segundo Gerhardt e Silveira (2009, p. 67):

[...] são realizadas com o intuito de descrever as características do fenômeno", ela [...] "exige do investigador uma série de informações sobre o que deseja pesquisar. Esse tipo de estudo pretende descrever os fatos e fenômenos de determinada realidade (TRIVIÑOS, 1987 ${ }^{10}$ apud GERHARDT; SILVEIRA, 2009, p. 35).

A pesquisa tem uma abordagem quanti-qualitativa, na qual se busca "trabalhar com dados de fácil quantificação e complementá-los com dados subjetivos ou descritivos" (BRUFEM; PRATES, $2005^{11}$ apud MELATI, 2013, p. 28), porém a base de dados, principalmente no item referente ao "breve histórico do Festival Halleluya", foi obtida via fonte primária de informações a partir da realização de entrevista semiestruturada com o organizador geral do evento. Ainda sobre a seção ora apresentada destaca-se que se optou pelo não uso de informações disponíveis em portais a exemplo do Wikipédia devido à confiabilidade das fontes utilizadas. Destaca-se ainda a presença de uma das autoras nas edições do evento o que culminou com a redação dos fatos apresentados.

A escolha pela tipologia estudo de caso objetivou levar "em consideração, principalmente, a compreensão, como um todo, do assunto investigado" (FACHIN, 2006, p. 45). Para tanto, a pesquisa in loco foi realizada de 11 a 27 de julho de 2015, na $19^{a}$ edição do Festival Halleluya em Fortaleza (Ceará/CE, Brasil). Na mesma, se teve o intuito de observar fatos e fenômenos da forma como ocorriam no local, o planejamento e a organização do festival, além de buscar dados referentes às seis edições anteriores, através de uma análise nos portais eletrônicos sugeridos pela organização do festival, haja vista ser possível ter acesso a informações a respeito do evento.

\footnotetext{
${ }^{10}$ TRIVIÑOS, A. N. S. Introdução à pesquisa em ciências sociais: a pesquisa qualitativa em educação. São Paulo: Atlas, 1987.

${ }^{11}$ BUFREM, L.; PRATES, Y. O saber científico registrado e as práticas de mensuração da informação. Ciência da Informação, Brasília, v. 34, n. 2, p. 9-25, 2005. Disponível em: <http://www.scielo.br/pdf/ci/v34n2/28551.pdf >. Acesso em: 14/05/2015.
} 


\section{ANÁLISE DE DADOS}

Aborda-se na presente seção um marco evolutivo da história do Festival Halleluya sendo perceptível sua expansão quanto a seu desenvolvimento e proporção; também se apresenta, à luz das teorias que tratam das fases dos eventos, o planejamento e a organização do referido evento. Finaliza-se com a apresentação de gráficos alusivos à evolução do festival em termos de público participante, estrutura organizacional, quantidade de horas de realização do evento e de atrações apresentadas em suas edições, além de números envoltos a itens referentes a ações de solidariedade, a saber: bolsas de sangue, doação de alimentos e cadastros de interessados em fazer parte do banco mundial de medula óssea.

\subsection{BREVE HISTÓRICO DO FESTIVAL HALLELUYA}

Constatou-se que o Festival Halleluya, ao longo dos anos, vem passando por transformações desde a própria nomenclatura, abrangendo também o crescimento do seu público, atrações, parceiros e sua infraestrutura, dentre tantos outros itens. De modo a prover um compêndio de informações que abarcassem a evolução do festival, apresentam-se a seguir os principais fatos correlatos aos anos de eventos já realizados.

No ano de 1995, o Projeto Juventude para Jesus da Comunidade Católica Shalom realizou uma festa no decorrer de três dias no Clube de Oficiais da Aeronáutica F 80, na cidade de Fortaleza/CE, denominada "Trifest" (COSTA, 2015). A mesma autora afirma que, animado por ministérios de música locais, o evento foi a semente do atual Festival Halleluya, acontecendo também em 1996.

Em 1997, o até então "Trifest" tomou maiores proporções, quando lideranças da Comunidade Católica Shalom tiveram a inspiração de oferecer aos jovens cearenses e turistas uma opção de lazer no final das férias (COSTA, 2015). Na mesma fonte consta que nascia, assim, o Halleluya, também chamado de "Quadrifest" neste ano, por ter na sua programação mais um dia de evento sendo realizado no parque do Cocó, na cidade de Fortaleza/CE.

No ano seguinte, em 1998, passou a ser chamado apenas de Halleluya, por já assumir a programação de cinco dias de evento (COSTA, 2015). A mesma autora afirma 
que o diferencial das edições de 1998 e 1999 foi o "Halleluya Beach", que aconteceu na Praia do Futuro, com jogos e outras atividades esportivas durante o dia e a noite. Também, como na edição anterior, o evento aconteceu no Parque do Cocó.

Em 2000, no ano Jubilar ${ }^{12}$, aconteceu o quarto Halleluya (COSTA, 2015). Nesse ano, a autora menciona que o evento recebeu o slogan que estava permanecendo até a edição estudada (2015), ou seja, "A festa que nunca acaba". Observa que o grande diferencial do ano de 2002 foi o início da vinda de caravanas de várias cidades do Ceará e até mesmo de outros estados do Brasil para participarem das noites de apresentações de música, teatro e dança no evento. Menciona que também é deste ano o estabelecimento da parceria com o Centro de Hematologia e Hemoterapia do Ceará, com o objetivo da coleta de sangue a partir de doadores participantes do evento.

No ano de 2003, consta em Costa (2015) que o Halleluya viria a ter seu primeiro portal eletrônico com o domínio "a festa". A autora afirma que se demonstrava já nesse ano uma desproporcionalidade em termos de espaço ora ocupado - Parque do Cocó versus a quantidade de público presente (cada vez maior). Em 2005, coloca que o Halleluya foi transferido para o Condomínio Espiritual Uirapuru - CEU e que cerca de 450 mil pessoas participaram do Halleluya em 2007. Uma das atrações desta edição foi a exposição das Relíquias de Santa Margarida Maria de Alacoque e fotografias marcantes dos 25 anos da Comunidade Católica Shalom (COSTA, 2015).

Foi a partir de 2010, em sua décima quarta edição, que o evento se transformou em festival e o público chegou a 800 mil pessoas nas cinco noites de realização. (LIMA, 2015). Incorporando outras linguagens artísticas, na mesma fonte se afirma que o evento possibilitou o surgimento de novos talentos no teatro e na dança. Também menciona que em 2012, o festival completou 15 anos de atividades e ainda marcou a comemoração dos 30 anos de fundação da Comunidade Católica Shalom, idealizadora, promotora e realizadora do evento.

O Festival Halleluya 2013 foi realizado como evento preparatório para a Jornada Mundial da Juventude, que aconteceu no Rio de Janeiro, e como atividade principal da Semana Missionária na Arquidiocese de Fortaleza (LIMA, 2015). No mesmo ano, em 25 de maio, o Festival Halleluya passou a integrar o calendário oficial de eventos do Estado do Ceará, através de um Projeto de Lei de autoria do presidente da Casa, José

\footnotetext{
${ }^{12}$ Celebração Cristã da Igreja Católica realizada a cada 25 anos.
} 
Albuquerque, aprovado por unanimidade pela Assembleia Legislativa, segundo o portal de notícias Shalom690 (2013).

Em 2014, Costa (2015) menciona que uma nova identidade visual, um novo layout da Arena (espaço onde aconteciam as atividades do festival) e uma maior interatividade com o público, que ajudou a escolher uma das atrações do evento, foram algumas das principais inovações. Também, que foi criada a hashtag Novo Halleluya (\#NovoHalleluya) para acompanhar a presença do festival, a partir do público participante, nas redes sociais. Nesse ano, obtiveram-se números expressivos em relação ao público com um total de 1.060 .000 (hum milhão e sessenta mil) pessoas (LIMA, 2015).

No ano de 2015, escolhido para a realização deste estudo de caso, a inovação foi a gravação do DVD da banda Missionário Shalom, a qual conseguiu reunir um público de 280 mil pessoas apenas na noite da gravação e um total de 1.000 .000 (hum milhão) de pessoas durante todo o evento, interagindo nos espaços oferecidos, a saber: Espaço da Solidariedade; Halleluya Kids e Arena Cultural subdividindo-se nos ambientes: Construtores da Sociedade/Pátio Halleluya, Halleluya Adventure, Fazendo Barulho, Cine Halleluya, Festival de Artes e Praça Quero Mais; Espaço da Misericórdia e Arena Halleluya (LIMA, 2015).

Posteriormente o Festival Halleluya aconteceu em várias localidades, a exemplo das cidades de Natal (Rio Grande do Norte/RN), São Luís (Maranhão/MA), Salvador (Bahia/BA), Aracaju (Sergipe/SE), São Paulo (São Paulo/SP) e Rio de Janeiro (Rio de Janeiro/RJ) e países, como Israel, Itália e Uruguai (LIMA, 2015).

\subsection{PLANEJAMENTO E ORGANIZAÇÃO DO FESTIVAL HALLELUYA À LUZ DA TEORIA DAS FASES DE UM EVENTO}

Neste tópico serão trazidas informações referentes às fases da organização do Festival Halleluya. Subdividir-se-á em pré-evento, evento e pós-evento e conterá informações coletadas durante a pesquisa de campo realizada de 11 a 27 de julho de 2015.

Antes de se explanar como estava sendo realizada a organização do evento, considerou-se de suma importância trazer o que seria o Festival Halleluya, segundo o organizador geral do festival: 
Um evento completo, feito para todos os públicos, dos mais jovens aos menos jovens. Nele nós temos a cultura, o esporte, a arte, a música, o teatro e a dança, espiritualidade, solidariedade. É um evento que promove o bem e exalta o bem, que previne das drogas, que mostra ao homem o que ele deve ser na sua existência, como ele deve se portar. (LIMA, 2015).

Desta maneira, apresentam-se as fases do evento, a saber:

a) Pré-Evento

Assim, como em todos os eventos, para o Festival Halleluya se realiza um planejamento estratégico antes mesmo do planejamento do evento em si. Nas palavras de Britto e Fontes (2004, p.14) este processo inicia-se com a compreensão de que a realização de um evento "envolve pesquisa, planejamento, organização, coordenação, controle e implantação de um projeto, visando atingir o seu público-alvo com medidas concretas e resultados projetados". À luz do caso estudado, por constatação pessoal de uma das autoras do presente artigo quando da participação na organização do evento, verificou-se que o festival possuía uma equipe, composta por nove pessoas, chamada de Comissão Central, responsável por seu planejamento e inovação.

A organização geral do evento estava composta pelas pessoas da Comissão Central acrescida por mais dez pessoas que trabalhavam no escritório de eventos da Comunidade Católica Shalom, em Fortaleza/CE (LIMA, 2015). Essas dez pessoas assumiram a coordenação de equipes como Marketing/Divulgação, Secretaria, Financeiro e Infraestrutura, a fim de que se centralizassem as coordenações das equipes responsáveis pela maior parte do pré-evento, conforme pôde ser visto na vivência de uma das autoras durante o período de observação participante.

Quando perguntado ao organizador geral do evento como se dava a formação da equipe de trabalho para a atuação no festival, constatou-se que nas áreas de marketing, design gráfico e comercial, por exemplo, o corpo de profissionais possuía experiência no desenvolvimento de atribuições correlatas à sua área de atuação no festival, porém também faziam parte do rol de trabalhadores pessoas que não possuíam experiência profissional anterior, mas que desenvolviam suas atribuições com afinco no evento. Relativo a itens concernentes a ações de marketing, dentre estas a divulgação do Halleluya nas diversas mídias em voga na sociedade, destaca-se que verificou-se existir um plano de divulgação do evento preparado por sua comissão central. Esse documento 
abarcava o cronograma de divulgação do festival, assim como as estratégias a serem utilizadas para se alcançar o público e parceiros do evento, por exemplo.

Esmiuçando os itens que estavam compondo a divulgação do Festival Halleluya, transpõe-se o conteúdo coletado quando da entrevista com o organizador geral do evento: "é feita uma mobilização, um lançamento do evento para a Comunidade Shalom, no qual as pessoas são envolvidas e todo o grupo a partir daí respira Halleluya" (LIMA, 2015). Ainda se destacou sobre a mídia espontânea a partir da procura dos veículos de comunicação junto à organização geral do evento, produzindo conteúdo a ser veiculado em mídias impressas, digitais e televisivas, além da criação de peças a serem utilizadas na divulgação do evento, com criação em conjunto das equipes de marketing e comercial.

Considerou-se relevante nesse item destacar a fala do entrevistado quando perguntado se "o Halleluya tinha uma marca já consolidada no estado e no Brasil? ". Tal assertiva buscou base nos escritos de Aaker et al. (2001), ao abordar que a marca serve também para consolidar e reforçar a lembrança de memórias agradáveis da experiência com uma destinação. Nesse sentido foi percebido na fala do entrevistado que a "marca Halleluya" já estava consolidada no estado do Ceará, bem como no Nordeste brasileiro, e que vinha crescendo no restante do Brasil. Considerou-se também importante destacar o acréscimo na resposta do entrevistado quanto à região Nordeste, haja vista uma gama do público participante deslocar-se dos estados vizinhos ao Ceará, por meio de caravanas, grupos de amigos e familiares, com o objetivo de vivenciar o festival.

No tocante a questões de ordem financeira, pelo fato de o festival não envolver um custo para entrada do seu público foi perguntado sobre as "fontes utilizadas na captação dos recursos". O entrevistado afirmou que o setor financeiro atuava diretamente sobre os resultados advindos das receitas obtidas nas vendas de alimentação, livraria, stands, estacionamento e brechó, além de contar com apoio de patrocinadores, como a Prefeitura Municipal de Fortaleza e do Governo do Estado do Ceará, pela Lei do Mecenato Estadual, e de submeter um projeto do Festival de Artes todos os anos à Lei de Incentivo à Cultura (Lei Rouanet), através da Portaria número 411, de $1^{\circ}$ de julho de 2014 (BRASIL, 2014). Com o intuito de finalizar a primeira parte da entrevista semiestruturada, no que se referia à etapa de pré-evento, foi perguntado sobre "as maiores dificuldades encontradas no planejamento e na organização do 
evento". O coordenador geral citou questões como o capital de giro insuficiente para atividades prévias à execução antes do evento em si; o fato de o festival ser realizado em local aberto e as chuvas causarem atrasos na montagem da infraestrutura, além de não possuir uma equipe dedicada exclusivamente à organização do festival.

Foi perceptível na observação participante, nesta fase de pré-evento, o encontro de todas as dificuldades relatadas pelo organizador nesta edição do Festival Halleluya. Um fato que chamou atenção foi a forma de solucionar esses problemas. Por se tratar de um evento religioso, toda a equipe recorria primeiramente às orações. Nesses momentos foi possível observar mais claramente a força da estrutura organizacional e a fé dos profissionais envolvidos, que ia além das dificuldades, confiando "na Providência Divina", pois "no final tudo dá certo".

\section{b) Evento}

A etapa "Evento" trata-se do momento mais esperado pelos participantes. As pessoas precisam participar de eventos para enfrentar a realidade do seu dia a dia, pois se a vida real é difícil, árdua, estável, rotineira, ali elas devem encontrar muitas emoções, uma experiência prazerosa e um desfecho imprevisível (MELO NETO, 2001, p. 41).

Essa experiência é a que o festival em estudo tenta trazer aos seus participantes, alcançando o campo das emoções primordialmente por toda religiosidade envolvida. Pôde ser facilmente percebida a influência deste evento na vida das pessoas participantes quando perguntado ao coordenado geral do Halleluya, "de onde vem os maiores grupos para a participação no Festival?’. Além da própria cidade de Fortaleza, ele afirmou virem do interior daquele estado e de muitos outros também do Nordeste (Rio Grande do Norte e Pernambuco) e do Sudeste.

Em vivência durante o período do evento, foi visto que em Fortaleza, na mesma data do festival, aconteceu outro evento de porte denominado 'Fortal'. Por ocorrerem em um mesmo período, poder-se-ia ocorrer uma espécie de concorrência entre os eventos. Nesse sentido questionou-se ao entrevistado "o porquê de o festival acontecer no mês de julho" visto que também estava sendo um mês fixo para a realização do carnaval fora de época. A resposta dada voltou-se a questões relativas a férias, além de 
ser um período de alta estação no destino que sediava o festival. Percebeu-se a ausência na resposta, por parte do entrevistado, de citar, por exemplo, algum impacto advindo do evento 'Fortal'. Ademais também foi mencionado ser um mês no qual muitos turistas estão em Fortaleza, por ser uma cidade litorânea, "isso acaba atingindo também estes turistas e não só o público fortalezense", concluiu.

Para que o público pudesse viver a realidade proposta pelo Festival Halleluya, todos os componentes das equipes que trabalhavam no evento precisavam estar em perfeita sintonia, pois "grande ou pequena, a equipe é a expressão do evento, e cada qual contribui para o seu sucesso ou o seu fracasso" (ALLEN et al., 2008, p. 45). Assim sendo, foi informado que se tratava de mais de seis mil voluntários, distribuídos em 70 equipes.

\section{c) Pós-evento}

Passada a realização do evento era chegada a hora da execução do seu pósevento. Esta etapa, de responsabilidade da equipe organizadora da atividade, significava o fechamento de todas as questões envoltas ao evento, além de sua desmontagem.

Analisando a realidade estudada, a reunião de pós-evento, onde aconteceu a sua avaliação, foi realizada inicialmente com os membros do escritório mais a comissão central. Em seguida, cada equipe de trabalho foi acionada a fim de que fizesse sua avaliação e posteriormente fosse entregue à comissão organizadora. De posse das avaliações dos profissionais atuantes no evento como um todo se realizava a sua avaliação geral feita em até dois meses depois da realização do festival. Findada esta etapa, iniciava-se um novo ciclo de preparação do festival, ou seja, a sua próxima edição.

Quando perguntando ao organizador geral do festival "quem tem acesso aos dados obtidos no pós-evento e como é feita a divulgação dos resultados?", obteve-se como resposta a realização de uma prestação de contas para toda a Comunidade Católica Shalom, sendo através dessa reunião, com todos os seus membros, apresentados dados sobre a consecução em si do evento através de registros fotográficos, "números da solidariedade", de evangelizados, média de público participante, além dos dados de pesquisa de satisfação gerados no decorrer do evento. 
Além disso, também se realizou uma coletiva de imprensa com a participação da Polícia Militar, Corpo de Bombeiros e Coordenação Geral do Evento objetivando tornar público os dados relativos à edição em voga do festival.

Ainda na perspectiva do pós-evento e sabendo que os patrocinadores e apoiadores são elementos fundamentais para a realização de um evento de porte como o do festival, foi perguntado ao entrevistado se estes atores também "recebiam relatórios finais elou prestação de contas". Como resposta, o organizador geral disse não existir uma prestação de contas financeira e sim uma apresentação a respeito da divulgação das marcas nos espaços que contemplavam o evento em si. Neste momento busca-se a continuidade da parceria com o apoiador ou patrocinador com vistas à próxima edição do festival.

Chamou a atenção das autoras o fato de o Festival Halleluya até os dias correntes da pesquisa não possuir um compêndio de informações (em versão pública) que versassem sobre suas edições. Nesse sentido, sentiu-se a necessidade de questionar junto ao entrevistado se "são sistematizados e arquivados todos os documentos específicos às realizações do evento". Em sua resposta o entrevistado informou ser confeccionado um relatório, contendo projetos, ofícios, liberações, contratos etc., sendo estes arquivados no escritório de eventos da Comunidade Shalom. Destaca-se que não foi possível o acesso aos mesmos por ser um documento interno da comissão organizadora de modo a ser possível analisar o conteúdo das informações.

Por fim, perguntou-se "quais objetivos ainda pretendem alcançar nas próximas edições do evento?", tendo-se obtido os seguintes itens como respostas: ampliar a área útil do evento (para isso seria preciso fazer um grande trabalho de terraplanagem e topografia no espaço onde ocorria o festival); inovar os espaços já existentes e criar novos; aumentar o público participante do evento nos dias de quarta-feira, quinta-feira, sexta-feira e domingo, pois o sábado já tinha sua capacidade máxima; ampliar os serviços de alimentação; crescer na criatividade e na inovação; ampliar os envolvidos na "solidariedade"; fazer com que o Festival Halleluya se tornasse ainda mais conhecido no Brasil.

Considerou-se que todos estes objetivos seriam passíveis de serem alcançados se bem planejados, ascendendo a real dimensão do evento. 


\subsection{EVOLUÇÃO DO FESTIVAL HALLELUYA}

A fim de se constatar a evolução do planejamento e organização do festival Halleluya nas edições de Fortaleza/CE, foram elaborados gráficos com dados de 2010 (quando o evento se transformou em festival) até 2015. Ressalta-se que a elaboração destes gráficos foi embasada em dados coletados através da comissão geral de organização do Evento, da Comunidade Shalom - promotora e realizadora do evento (2015) e dos portais eletrônicos do festival e do Centro de Hematologia e Hemoterapia do Ceará (HEMOCE, 2015a). Destaca-se que o principal fator limitador para a construção destes residiu no fato da escassa publicação de dados concernentes ao evento, seja através de produções bibliográficas ou em mídias digitais, por exemplo.

O gráfico 1, intitulado como "números do Festival Halleluya" oferece dados referentes à estrutura organizacional, à quantidade de horas de realização do evento e de atrações apresentadas no palco principal nas seis últimas edições.

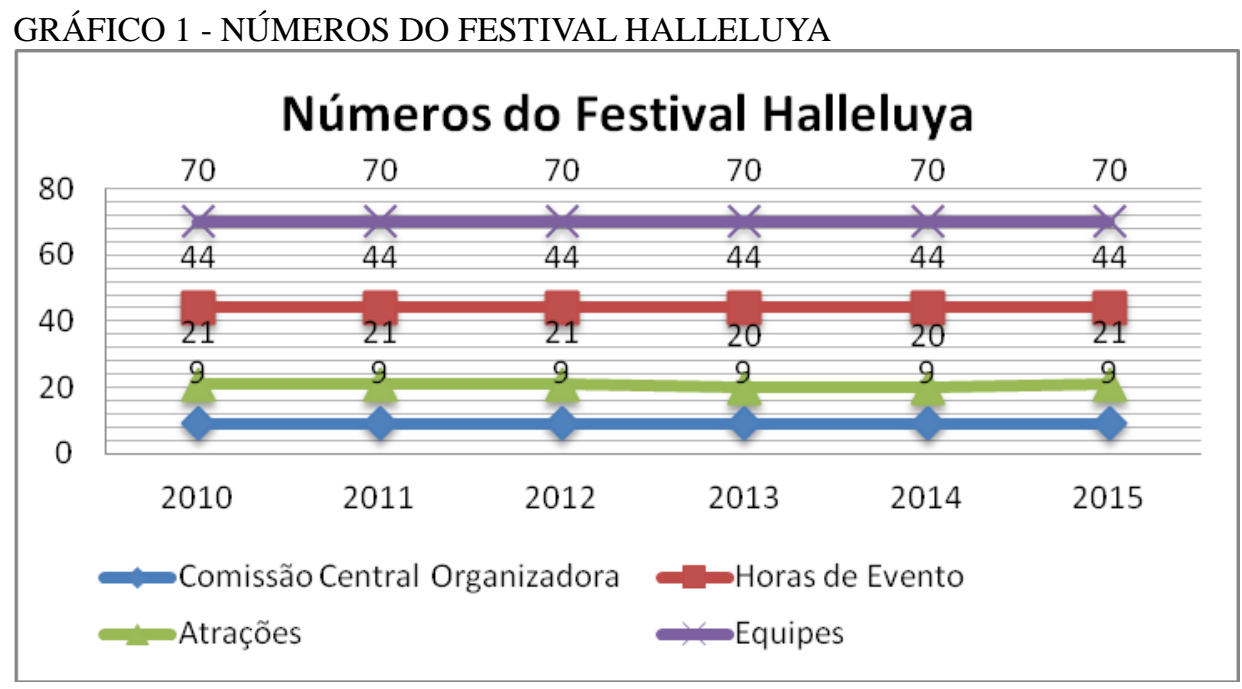

FONTE: Costa (2015).

Todos os dados desse gráfico mostraram-se constantes, com poucas alterações nos anos escolhidos para a realização do estudo. Aqui, considerou-se poder ser ousado ao afirmar que estes itens (comissão central organizadora, horas de evento, atrações e equipes) tornaram-se fixos e alterações neste quadro poderiam influenciar diretamente o evento, principalmente no número de público e de renda, pois ampliando-se a quantidade de horas de evento o mesmo poderia vir a receber mais público e, 
consequentemente, gerar mais renda. Porém, para que isto ocorresse, se considerou ser necessário um estudo prévio de demanda.

Referente à Comissão Central, pôde-se notar através da observação participante pouca rotatividade nesta equipe, sendo esta composta por autoridades da Comunidade Católica Shalom.

A quantidade de horas de realização do evento e as atrações tornaram-se fixas conforme disposto no gráfico, assim como as 70 equipes existentes, por ser esta quantidade suficiente para que o evento acontecesse.

Relativos aos números envoltos às questões da solidariedade (nomenclatura utilizada pela organização do evento para tratar de itens de doação e coleta de sangue, por exemplo) observou-se que os participantes eram incentivados, no decorrer dos dias do festival, a levarem um quilo de alimento não perecível, assim como também a se cadastrarem no banco mundial de medula óssea ou até mesmo doar sangue (ver GRÁFICO 2).

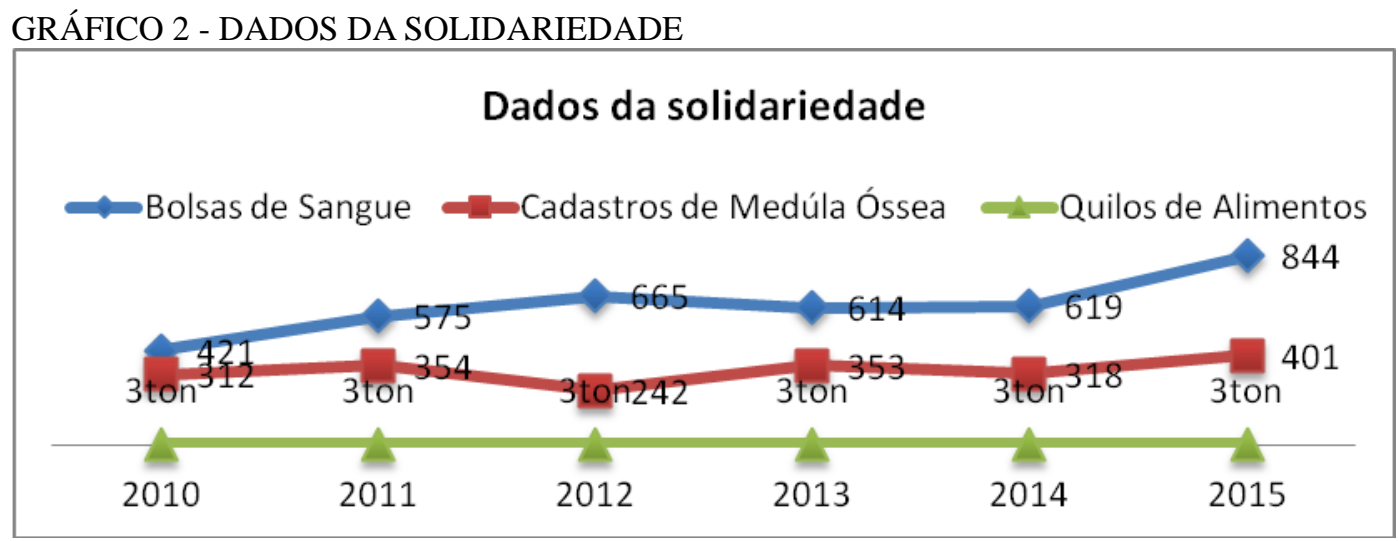

FONTE: Costa (2015).

Os dados referentes à quantidade de bolsas de sangue arrecadadas e aos cadastros no banco de medula óssea foram obtidos através do portal eletrônico (HEMOCE, 2015b). Percebeu-se que até 2014 esses dados foram variáveis e no ano de 2015 existiu um acréscimo considerável, principalmente na quantidade de bolsas de sangue coletadas. A meta estabelecida para a edição estudada foi de 800 , tendo sido este número ultrapassado em 44 unidades. Corroborando sobre a importância da coleta de dados, o Hemocentro, em entrevista ao portal de notícias G1 (2015), afirmou ser a coleta efetuada no Festival Halleluya necessária para o restabelecimento dos estoques de sangue que usualmente tinham um decréscimo em período de férias. 
Tratando especificamente da coleta de alimentos, os dados apresentados pela organização geral do festival asseguraram 3 toneladas obtidas, contudo, dada a imprecisão desta informação em edições anteriores ao evento, não foi possível estabelecer uma evolução ou não destes.

A partir da análise dos dados relativos ao público participante do Festival Halleluya (GRÁFICO 3), percebeu-se inicialmente uma estagnação na quantidade deste nas quatro últimas edições. Desta feita, apontaram-se os anos de 2010 a 2012 como sendo àqueles envoltos a fase da consolidação, de "estagnação" em 2013, com um crescimento (reduzido) em 2014 e estabilização no ano de 2015.

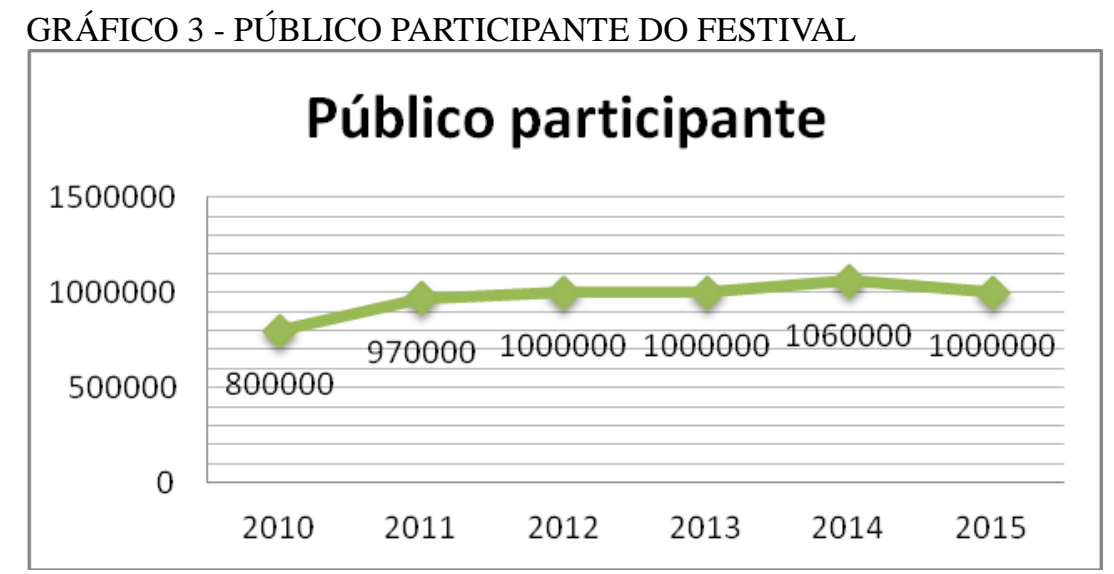

FONTE: Costa (2015).

Observou-se que para o evento poder adentrar em uma nova fase e assim expandir-se a questão problematizadora não estaria na divulgação ou nas atrações apresentadas, mas na capacidade de carga que o local de realização do evento poderia receber. A solução estaria diretamente ligada à observação feita pelo organizador geral, quando abordou alguns dos objetivos para as próximas edições do festival, sendo o primeiro: "ampliar a área útil do evento".

Foi possível observar a preocupação da organização em busca de um 'rejuvenescimento' quando o entrevistado comentou que "este público é mantido por uma regra básica existente em todos os eventos, 'se renovar sempre', pois, todo evento deve apresentar novidades e atrações de peso", assegurou. De fato, concordou-se com o entrevistado, em que a captação de novos participantes perpassaria pela atratividade em si do evento e que o estímulo a uma nova demanda careceria de esforços por parte de sua comissão organizadora quando da formatação de sua proposta. 


\section{CONSIDERAÇÕES FINAIS}

Através do presente estudo considerou-se que foi possível comprovar que o setor de eventos, o qual compõe a cadeia produtiva do turismo, é um fenômeno crescente que está tomando proporções cada vez maiores e ganhando destaque e espaço na sociedade.

Os eventos tornaram-se momentos oportunos para o divertimento da sociedade em geral e muitas vezes até um conhecimento científico, cultural, religioso, entre outros. Mas, a fim de que isto ocorra, são sempre necessários planejamento e organização para eventos de grande, médio ou de pequeno porte.

O estudo de caso realizado no festival cultural-religioso intitulado como "Festival Halleluya" serviu para explicitar como estava acontecendo na prática a organização deste megaevento, dividindo-o nas três fases como citado na teoria (préevento, evento e pós-evento), além de trazer uma análise da evolução das suas seis últimas edições de modo a alcançar o objetivo central proposto do estudo quanto à sistematização de informações a referente ao planejamento e organização do evento.

Fundamentalmente, foi visto no histórico que o Halleluya se iniciou com proporções muito menores e que, ao longo das realizações de novas edições, o evento foi se transformando no maior festival cultural-religioso (chamado pela organização geral do evento de Festival de Artes Integradas) da América Latina.

$\mathrm{Na}$ fase de pré-evento foi possível comprovar existir uma Comissão Central responsável pelo planejamento e inovação do festival e uma equipe que trabalhava no escritório de eventos da Comunidade Católica Shalom, as quais atuavam na organização geral do evento. As formações profissionais desta equipe eram extremos opostos, alguns possuindo a formação exatamente na área em que estavam atuando e outros nunca tendo realizado um evento sequer, onde tentavam aprender tudo na prática.

Além de receberem uma grande ajuda por parte da mídia espontânea, verificouse existir uma preocupação por parte da organização geral do evento para com as ações de marketing e divulgação, tendo inclusive sido formatado um plano de divulgação do evento.

Também se constatou que o patrocínio de grandes empresas e submissões de projetos a leis de incentivo colaboraram para que o festival com tal magnitude acontecesse. 
Considera-se que na fase de realização do evento, no mês de julho por estratégia da organização, foi possível alcançar o campo das emoções dos participantes, tanto por sua cultura quanto pela religiosidade envolvida a tal ponto de influenciar a ida de pessoas até mesmo de outros estados brasileiros à cidade de realização do evento. Também foi identificado que o quadro de profissionais envolvidos na realização do festival era composto por voluntários.

Na última etapa foi perceptível uma preocupação por parte da organização geral para a realização das reuniões pós-evento, além de uma divulgação de resultados mais interna para a Comunidade Católica Shalom e uma coletiva de imprensa.

Os gráficos elaborados com dados de 2010 a 2015, com o intuito de analisar a evolução do planejamento e organização do Festival Halleluya nas edições de Fortaleza/CE, mostraram-se constantes, com poucas alterações nos anos escolhidos para a realização do estudo, considerando-se poder afirmar que a sua estrutura se tornou fixa.

Por fim, percebeu-se uma consolidação na quantidade de público participante de 2010 a 2012, uma estagnação em 2013, um crescimento reduzido em 2014 e uma estabilização no ano de 2015 , porém a solução para este problema estaria diretamente ligada à ampliação da área útil do evento.

Face ao exposto no decorrer desse estudo, foi possível constatar que o evento em sua décima nona edição encontrava-se consolidado na cidade de Fortaleza/CE podendo servir de modelo para as outras edições realizadas no Brasil e no mundo.

\section{REFERÊNCIAS}

AAKER, D. A.; KUMAR, V.; DAY, G. S. Pesquisa de Marketing. São Paulo: Atlas, 2001.

AGUIAR, M. R. de; DIAS, R. Fundamentos do turismo: conceitos, normas e definições. Campinas, SP: Editora Alínea, 2002.

ALLEN, J. et al. [Tradução de Marise Philbois e Adriana Kramer]. Organização e gestão de eventos. 3. ed. Rio de Janeiro: Elsevier, 2008.

ANDRADE, I. da S. Apropriação do Turismo nas manifestações populares: Festa do Divino Espírito Santo em Paraty / RJ. 2008. 98 f. Trabalho de Conclusão de Curso (Bacharel) - Curso de Turismo, Universidade Federal Fluminense, Niterói, 2008. 
ANDRADE, J. V. de. Turismo: fundamentos e dimensões. São Paulo: Ática, 2002.

ARAGÃO, I.; MACEDO, J. R. de. Turismo religioso, patrimônio e festa: Nosso Senhor dos Passos na cidade sergipana de São Cristóvão. Caderno Virtual de Turismo, Rio de Janeiro, v. 11, n. 3, p. 399-414, dez. 2011.

ABEOC BRASIL - Associação Brasileira de Empresas de Eventos. II Dimensionamento Econômico da Indústria de Eventos no Brasil - 2013. Disponível em: <http://www.abeoc.org.br/2014/10/ii-dimensionamento-economico-da-industria-deeventos-no-brasil/>. Acesso em: 01/06/2015.

BARBOSA, F. S. Planejamento Estratégico para Eventos: Um estudo de caso das estratégias de Marketing utilizadas pela Oktoberfest de Santa Cruz do Sul/Rs. Cultur Revista de Cultura e Turismo, Bahia, ano 7, n. 14, p. 87-104, fev. 2013.

BRASIL. Congresso Nacional. Senado Federal. Coordenação de Relações Públicas. Manual de organização de eventos do Senado Federal. 1. ed. Brasília : Senado Federal, 2013.

BRASIL. Ministério da Cultura, Secretaria de Fomento e Incentivo à Cultura. Portaria n. 411, de 01 de julho de 2014. Aprova o(s) projeto(s) cultural(is), relacionado(s) no(s) anexo(s) desta Portaria, para o(s) qual(is) o(s) proponente(s) fica(m) autorizado(s) a captar recursos, mediante doações ou patrocínios, na forma prevista no $\S 1^{\circ}$ do artigo 18 e no artigo 26 da Lei n. ${ }^{\circ} 8.313$, de 23 de dezembro de 1991, alterada pela Lei $n^{\circ} 9.874$, de 23 de novembro de 1999. Disponível em:

$<$ http://pesquisa.in.gov.br/imprensa/servlet/INPDFViewer?jornal=1\&pagina=19\&data= 02/07/2014\&captchafield=firistAccess $>$. Acesso em: 01/07/2015.

BRASIL. Ministério do Turismo, Secretaria Nacional de Políticas de Turismo, Departamento de Estruturação, Articulação e Ordenamento Turístico, CoordenaçãoGeral de Segmentação. Turismo Cultural: orientações básicas. 3. ed. Brasília: Ministério do Turismo, 2010.

BRITTO, J.; FONTES, N. Estratégias para eventos: uma ótica do marketing e do turismo. São. Paulo: Aleph, 2004.

CARDOSO, M. L. A Importância da Organização de Eventos no Turismo. 2013. 81

f. Tese (Doutorado) - Curso de Turismo, Faculdade de Letras da Universidade do Porto, Porto, 2013.

CESCA, C. G. G. Organização de Eventos: Manual para planejamento e execução. 11 ed. Ver. E atual. São Paulo: Summus Editorial. 2008.

COMSHALOM. Abril em Brasília: Shalom realiza festival Capital da Paz. Disponível em: <http://www.comshalom.org/brasilia-recebe-festival-capital-da-paz-em-abril/>. Acesso em: 01/05/2015. 
COSTA, D. C. Planejamento e organização de eventos religiosos: Um estudo de caso do Festival Halleluya - Fortaleza/CE. 90 p. Monografia (Graduação em Turismo) Departamento de hotelaria e turismo, Universidade Federal de Pernambuco, Recife, 2015.

EMBRATUR. Plano Aquarela 2020. Disponível em:

<www.turismo.gov.br/export/sites/default/.../Plano_Aquarela_2020.pdf.>. Acesso em: 30/04/2015.

FACHIN, O. Fundamentos de metodologia. 5. ed. [rev.]. São Paulo: Saraiva, 2006.

FESTIVAL HALLELUYA. Festival Halleluya supera 1 milhão de participantes. Disponível em: <http://festivalhalleluya.org/fortaleza/festival-halleluya-supera-1milhao-de-participantes/>. Acesso em: 15/03/2015.

FERREIRA, L. D. M. Festas religiosas: Uma manifestação cultural de Mariana. Ouro Preto: ETFOP, 2009.

G1. Hemoce bate recorde de doação de sangue no Halleluya, em Fortaleza. Disponível em: <http://g1.globo.com/ceara/noticia/2015/07/hemoce-bate-recordededoacao-de-sangue-no-halleluya-em-fortaleza.html>. Acesso em: 30/07/2015.

GETZ, D. Event Management and Event Tourism. 29. ed. New York: Cognizant Communications, 2008.

GERHARDT, T. E.; SILVEIRA, D. T. (Org.). Universidade Aberta do Brasil UAB/UFRGS; Curso de Graduação Tecnológica - Planejamento e Gestão para o Desenvolvimento Rural da SEAD/UFRGS (Coord.). Métodos de pesquisa. Porto Alegre: Editora da UFRGS, 2009.

HEMOCE. Halleluya 2011 supera número de doações das últimas edições. Disponível em: <http://www.hemoce.ce.gov.br/index.php/item-c-subitem/noticias/46871-parcerias>. Acesso em: 15/03/2015a.

HEMOCE. Hemoce coleta mais de 600 bolsas de sangue no Halleluya. Disponível em: <http://www.hemoce.ce.gov.br/index.php/item-c-sub-item/noticias/46517-hemoceconquista>. Acesso em: 15/03/2015b.

HOELER, E. H. Turismo de eventos: Centreventos Cau Hausen de Joinville -SC. In: ANSARAH, M. G. dos R. (Org.). Turismo, segmentação de mercado. São Paulo: Futura, 2000, p. 75-91.

LAKATOS, E. M.; MARCONI, M. de A. e. Fundamentos de metodologia científica. 5. ed. São Paulo: Atlas, 2003.

LIMA, F. Festival Halleluya. [11 jul.2015]. Entrevistador: Débora Cristina Costa. Fortaleza,2015. 1 arquivo.mp3 ( $90 \mathrm{~min}$.). 
MACIEL, B. P. Festivais de Música e Turismo dois estudos de caso: Les Aralunaires e Milhões de Festa. 2011. 95 f. Dissertação (Mestrado) - Curso de Turismo, Faculdade de Letras da Universidade do Porto, Porto, 2011.

MELATI, C. Socialização organizacional na secretaria da administração e dos Recursos humanos do Rio Grande do Sul. 2013. 56 f. Trabalho de Conclusão de Curso (Especialista) - Administração pública contemporânea. Universidade Federal do Rio Grande do Sul, Porto Alegre, 2013.

MELO NETO, F. P. de. Marketing de Eventos. 3. ed. Rio de Janeiro: Sprint, 2001.

MOLINA, M. M. El papel del turismo de eventos en el desarrollo urbano. El caso de Expo Zaragoza. Revista de turismo y patrimônio cultural, v. 11, n. 1, 2013, p. 57-71. 2013.

POIT, D. R. Organização de eventos esportivos. 4. ed. São Paulo: Phorte, 2006.

SILVEIRA, E. J. S. da; DIAS, R.. Turismo Religioso: ensaios e reflexões. Campinas: Alínea, 2003.

STOCK, L. T. Logística Integrada em Eventos: um estudo de caso do Festival de Dança de Joinville/SC. Dissertação (Mestrado em Turismo e Hotelaria). Universidade do Vale do Itajaí, Balneário Camboriú, 2009.

VIDAL, R. P.; RIEDL, M. A influência do turismo de eventos na Região das Hortênsias, Rio Grande do Sul, (Brasil): o caso do evento Natal Luz de Gramado. Turismo e Sociedade, [S.1.], v. 9, n. 3, dez. 2016. ISSN 1983-5442. Disponível em: <http://revistas.ufpr.br/turismo/article/view/47709/31545>. Acesso em: 07/07/2017.

WRAGG, D. Relações públicas em marketing e vendas: uma abordagem gerencial. São Paulo: McGraw-Hill, 1989.

ZANELlA, L. C. Manual de organização de eventos: planejamento e operacionalização. São Paulo: Atlas, 2003.

Recebido em: 04-03-2017.

Aprovado em: 03-04-2017. 